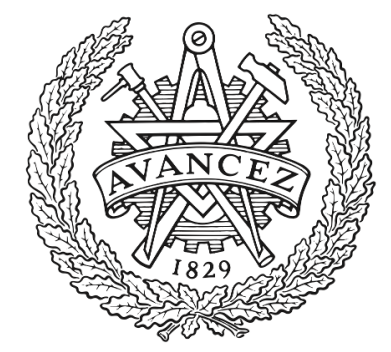

\title{
CHALMERS
}

UNIVERSITY OF TECHNOLOGY

\section{Dish-Stirling Solar Power Plants: Modeling, Analysis and Control of Receiver Temperature}

Downloaded from: https://research.chalmers.se, 2023-04-26 11:23 UTC

Citation for the original published paper (version of record):

Li, Y., Choi, S., Yang, C. (2014). Dish-Stirling Solar Power Plants: Modeling, Analysis and Control of Receiver Temperature. IEEE Transactions on Sustainable Energy, 5(2): 398-407.

http://dx.doi.org/10.1109/TSTE.2013.2291572

N.B. When citing this work, cite the original published paper.

(O2014 IEEE. Personal use of this material is permitted.

However, permission to reprint/republish this material for advertising or promotional purposes 


\title{
Dish-Stirling Solar Power Plants: Modeling, Analysis and Control of Receiver Temperature
}

\author{
Yang Li, Student Member, IEEE, San Shing Choi, Senior Member, IEEE, and Chun Yang
}

\begin{abstract}
A simplified adiabatic model of the Stirling engine is developed for the study of grid-connected dish-Stirling solarthermal power plant. The model relates the average values of the engine state variables and also takes into account engine losses. As the engine is shown to exhibit nonminimum phase behavior, an improved temperature control scheme for the engine heat absorber is developed. By including engine speed, pressure and solar insolation limits into the analysis, steady-state feasible operating regime of the solar-thermal power plant is obtained. Maximum solar energy harness is shown to be achievable through variable speed operation of the power plant.
\end{abstract}

Index Terms-Concentrated solar power, dish-Stirling (DS) system, temperature control.

\section{NOMENCLATURE}

Symbol:

$\begin{array}{ll}A & \text { Area }\left(\mathrm{m}^{2}\right) \text {. } \\ \mathrm{D} & \text { Derivative operator } d / d \phi . \\ I & \text { Solar insolation }\left(\mathrm{W} / \mathrm{m}^{2}\right) . \\ M & \text { Total mass of working gas in the cylinder }(\mathrm{kg}) \text {. } \\ P & \text { Power }(\mathrm{W}) . \\ Q & \text { Heat }(\mathrm{J}) . \\ R & \text { Gas constant }\left[\mathrm{m}^{3} \cdot \mathrm{Pa} /(\mathrm{K} \cdot \mathrm{kg})\right] . \\ T & \text { Temperature }(\mathrm{K}) . \\ V, v & \text { Volume }\left(\mathrm{m}^{3}\right) . \\ W & \text { Work }(\mathrm{J}) . \\ g A & \text { Mass flow rate }(\mathrm{kg} / \mathrm{s}) . \\ m & \text { Mass of the working gas }(\mathrm{kg}) . \\ p & \text { Pressure of the working gas }(\mathrm{Pa}) . \\ \alpha & \text { Initial crank angle }(\mathrm{rad}) . \\ \gamma & \text { Specific heat ratio. } \\ \eta & \text { Efficiency. } \\ \phi & \text { Crank angle (rad). } \\ \eta & \text { Efficiency. } \\ \omega & \text { rotational speed }(\mathrm{rad} / \mathrm{s}) .\end{array}$

Subscript:

c Compression space.

cl Clearance.

ck Compression space-cooler interface.

con Concentrator.

$e \quad$ Expansion space.

$h \quad$ Heater or thermal input.

Yang Li and San Shing Choi are with the School of Electrical and Electronic Engineering, Nanyang Technological University, Singapore 639798, Singapore (e-mail: yangli@ieee.org; esschoi@ntu.edu.sg).

Chun Yang is with the School of Mechanical and Aerospace Engineering, Nanyang Technological University, Singapore 639798, Singapore (e-mail: mcyang@ntu.edu.sg).

$\begin{array}{ll}\text { he } & \text { Heater-expansion space interface. } \\ k & \text { Cooler. } \\ \mathrm{kr} & \text { Cooler-regenerator interface. } \\ m & \text { Mechanical. } \\ r & \text { Regenerator. } \\ \mathrm{rec} & \text { Receiver. } \\ \mathrm{rh} & \text { Regenerator-heater interface. } \\ \mathrm{sw} & \text { Swept space. }\end{array}$

\section{INTRODUCTION}

$\mathbf{T}$ HERE is immense development opportunity for the renewable energy sources, in which the dish-Stirling (DS) solar-thermal generation system is one type. This solar-thermal power plant uses a parabolic mirror-like reflector dish to concentrate sunlight to a small area located at the focal point of the mirrors. High temperature achieved at the focal point is used as a heat source for a Stirling engine. The Stirling engine is capable of operating at high efficiency and releases no emissions, making it highly compatible with the solar thermal power technology [1], [2].

Unfortunately, the often random and uncontrollable nature of solar irradiance poses a challenge in the control of the DS power plant. Careful control system design based on suitably developed model for the DS power plant is thus called for. Indeed, an integrated DS system model was proposed in [3] and its control system was investigated in [4]. A variable-speed DS scheme was studied for the purpose of achieving maximum solar power harness in [5], but control of the temperature of the DS system was not discussed. In fact, the control of the temperature of the heat absorber is one most important consideration in the design of the power plant. Towards this end, a rather empirical temperature control scheme had been proposed in [6] for a particular type of Stirling engine. While there are many newer types of Stirling engine being studied in recent years [7]-[9], most of the reported works focused on developing suitable models for kinematic type of Stirling engine using ideal adiabatic analysis and with the inclusion of various forms of thermal losses [10]-[12]. These high-order nonlinear models are relatively accurate and are expressed in the form of boundary-value equations. Unfortunately, the step-size required to obtain accurate numerical solution of the equations is often incompatible with that used in the power system studies. Furthermore, these models consider internal thermodynamic behaviors which may not need to be considered in the design of the absorber temperature control systems. Often the developed models also require detailed knowledge of the Stirling engine, e.g., engine dimension and 
the characteristics of the working gas, information which is unlikely to be available during the planning stage of a DS system.

In this paper, the basic working principle of the DS system is described in Section II, from which a simplified averagevalue model for the engine shall be derived in Section III. Based on the developed model, the design of a temperature control scheme for the heat absorber of the DS system will be described in Section IV. Section V contains an analysis of the DS system under steady-state operation. Potential of variable speed operation of the DS system to maximize energy harness will be discussed. Numerical examples are used in Section VI to illustrate the main findings of the present investigation.

\section{Dish-StiRling System: Some BASICS}

Essentially, three energy conversion processes are involved in a typical DS system [1]. First, the direct normal irradiance collected by the dish concentrator is reflected onto a small hollow chamber called the receiver. In the receiver, the harnessed solar energy is in turn converted to thermal energy and then absorbed by a large number of metallic tubes called absorber. Second, the Stirling engine converts the absorbed thermal energy into mechanical energy by compressing and expanding a working gas, such as hydrogen and helium. Finally, the Stirling engine drives an electric generator which converts the mechanical energy into electricity.

The concentrated solar power intercepted by the receiver is converted into heat, i.e.,

$$
\dot{Q}_{I}=\eta_{\mathrm{con}} A_{\mathrm{con}} I
$$

where $A_{\text {con }}$ is the projection area of the concentrator and $I$ is the insolation level. $\eta_{\text {con }}$ is the overall efficiency of the concentrator and its value depends on the reflectivity of the concentrator surface, among other factors. Normally $\eta_{\text {con }}$ and $A_{\text {con }}$ can be considered constant. Note that the symbol $\dot{Q}$ is used here to represent thermal power quantity. Only part of $\dot{Q}_{I}$ shall be absorbed by the Stirling engine. The absorbed power is denoted as $\dot{Q}_{h}$ which is determined by the dynamic characteristic of the Stirling engine and is traditionally calculated using complex high-order nonlinear thermodynamic models, e.g. the ideal adiabatic model. The balance of the thermal power $\left(\dot{Q}_{L}\right)$ will be lost to the surrounding atmosphere through conduction, convection and radiation.

The imbalance between $\dot{Q}_{I}$ (input power) and $\dot{Q}_{L}+\dot{Q}_{h}$ (output power) will cause a temperature change on the absorber [13]. Mathematically,

$$
\begin{aligned}
\dot{Q}_{L} & =K_{L}\left(T_{h}-T_{a}\right) \\
K_{r} \frac{d T_{h}}{d t} & =\dot{Q}_{I}-\dot{Q}_{L}-\dot{Q}_{h} .
\end{aligned}
$$

In (2) and (3), $T_{h}$ denotes the temperature of the absorber tubes. $T_{h}$ is considered uniform in the whole space of the absorber wall and equals to the average temperature of the working gas in the tubes [4]. Constant $T_{a}$ is the temperature of the atmosphere. $K_{r}$ and $K_{L}$ are two constants whose values depend on the characteristic of the absorber material [14].

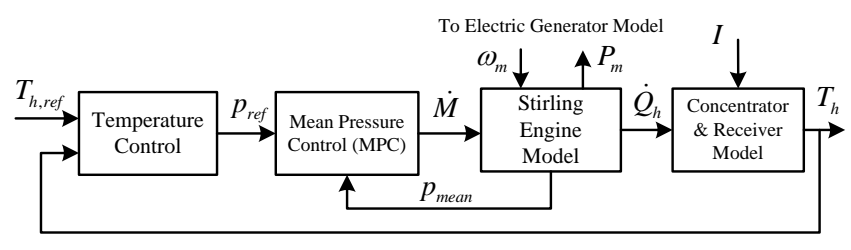

Fig. 1. Block diagram of DS absorber temperature control scheme.

Substituting (1) and (2) into (3), and in the $s$-domain representation, the concentrator-receiver model is

$$
T_{h}(s)=\frac{\eta_{\mathrm{con}} A_{\mathrm{con}} I(s)+K_{L} T_{a}-\dot{Q}_{h}(s)}{K_{L}+K_{r} s} .
$$

Unlike other applications of the Stirling engine, the 'fuel' supplied to the DS system, i.e., the solar insolation $I$, is intermittent. It can be seen from (4) that a change of $I$ will cause variation in the temperature $T_{h}$. As controlling $T_{h}$ to acceptable value is one most important task in the operation of the DS system, $\dot{Q}_{h}$ must be regulated appropriately. Among the many types of Stirling engine and methods to control $\dot{Q}_{h}$ described in [15], only the double-acting kinematic engine with variable mean pressure control (MPC) scheme is studied here as it is the most developed and effective configuration in current applications [1]. The basic MPC concept for temperature control can be explained using Fig. 1. The three variables, mean pressure $p_{\text {mean }}$ of the working gas, engine speed $\omega_{m}$ and $T_{h}$, describe the behavior of the Stirling engine. $p_{\text {mean }}$ is shown to be approximately proportional to the total mass $M$ of the working gas in the cylinders of the Stirling engine [12]. Thus, by operating a set of valves, $p_{\text {mean }}$ can be controlled by either supplying or dumping the working gas. The MPC system could therefore be studied using the block diagram shown in Fig. 2 where the approximately linear relationship between $p_{\text {mean }}$ and $M$ is represented by the constant gain $K_{p}$. The singlelag block is used to represent the fast-responding solenoid valves which regulate the mass flow rate $\dot{M}$ according to the valve command. The proportional controller $G_{p}$ regulates $p_{\text {mean }}$. Tuning method for $G_{p}$ is given in [4]. Noting that for the solenoid valves, $T_{v} \ll 1 \mathrm{~s}$, the simplified transfer function $p_{\text {mean }}(s) / p_{\text {ref }}(s)$ or $G_{\text {mpc }}(s)$ is also shown in Fig. 2.

MPC can be considered as the inner loop of the temperature control shown in Fig. 1. Hitherto, the design of the temperature controller has been carried out in an empirical manner as no suitable model of the Stirling engine has been developed for this purpose. Thus, unlike the approach of [4] and as shown in Fig. 2 where only approximate linearized mean pressure model is used, the present work is to firstly establish the analytical relationship governing $\dot{Q}_{h}$ and $p_{\text {mean }}$ and then utilize the gained insight to design a superior control system for $T_{h}$, as shown in the following sections.

\section{Developed Stirling Engine Model}

\section{A. Average-Value Adiabatic Model}

It is usually convenient to normalize system variables when developing models for power system studies. Thus, the following base values will be used: $\omega_{m \text {, base }}=\omega_{m, N}$, the 


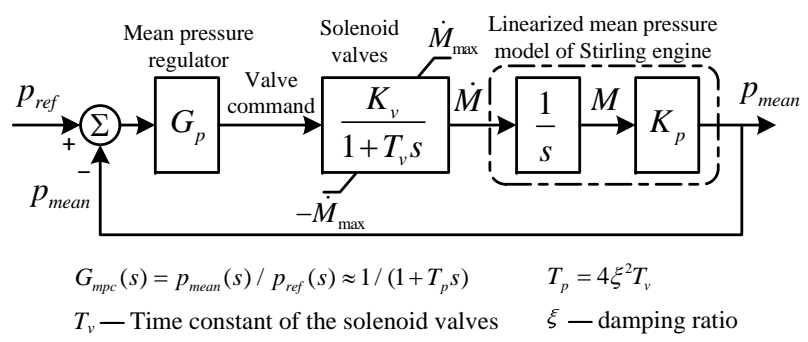

Fig. 2. Block diagram of MPC within the temperature control scheme.

nominal engine speed $(\mathrm{rad} / \mathrm{s}) ; p_{\text {base }}=p_{\max }$, the maximum pressure limit $(\mathrm{Pa}) ; P_{\text {base }}=\dot{Q}_{\text {base }}=P_{m, N}$, the nominal output power of Stirling engine $(\mathrm{W}) ; T_{\text {base }}=T_{h, \text { max }}$, the maximum heater temperature $(\mathrm{K}) ; I_{\text {base }}=I_{\max }$, the maximum insolation $\left(\mathrm{W} / \mathrm{m}^{2}\right)$. Henceforth, analysis will be conducted on per-unit basis and the symbol "-" is appended to denote p.u. values.

Starting from the ideal adiabatic model of the Stirling engine, the authors have derived a new and simplified model which includes the transfer functions between the time-average values of the Stirling engine output power $\bar{P}_{m, \text { adi }}$ with mean pressure $\bar{p}_{\text {mean }}$, and that of the engine absorbed (input) power $\dot{Q}_{h \text {,adi }}$ with $\bar{p}_{\text {mean }}$. The detailed derivation is shown in the Appendix. The developed transfer functions are

$$
\begin{aligned}
G_{m}(s) & =\frac{\bar{P}_{m, \text { adi }}(s)}{\bar{p}_{\text {mean }}(s)}=\bar{K}_{m} \bar{\omega}_{m} \frac{1}{1+T_{\mathrm{se} 3} s} \\
G_{h}(s) & =\frac{\bar{Q}_{h, \text { adi }}(s)}{\bar{p}_{\text {mean }}(s)}=\bar{K}_{h} \bar{\omega}_{m} \frac{1-T_{\mathrm{se} 1} s}{1+T_{\mathrm{se} 2} s}
\end{aligned}
$$

where positive parameters $\bar{K}_{m}, \bar{K}_{h}$, and $T_{\text {sel }}$ are as defined in the Appendix. As shown in the Appendix, these parameters are functions of the temperature. However, as shall be shown later, the purpose of the temperature control system is to allow the temperature to vary in a very narrow band. Therefore such small temperature variations are considered to have negligible effect on the performance of the engine. From (6) and the Appendix, note that the transfer function $G_{h}(s)$ relating $\dot{Q}_{h \text {,adi }}$ and $\bar{p}_{\text {mean }}$ is a first-order nonminimum phase system. Also, both the gain $\bar{K}_{h} \bar{\omega}_{m}$ and the time constant $T_{\text {sel }}$ are functions of engine speed $\bar{\omega}_{m} \cdot T_{\mathrm{se} 2}$ and $T_{\mathrm{se} 3}$ are time constants which embody the first-order filtering effect when determining the average values of the variables. Values of $T_{\mathrm{se} 2}$ and $T_{\mathrm{se} 3}$ are selected to be compatible with the power system phenomenon studied.

There is still another consideration: the analysis from which (5) and (6) are derived does not consider most types of thermal and frictional losses. Thermal efficiency of practical Stirling engine can be as low as half of that determined based on the ideal adiabatic analysis [12]. Thus losses have to be considered and this can be done by modifying the steady-state gain $\bar{K}_{m}$ and $\bar{K}_{h}$ in (5) and (6), as shown next. This is a new method of incorporating the losses when developing the Stirling engine model in grid-related studies.

\section{B. Inclusion of Steady-State Thermal and Frictional Losses}

It is clear from (5) and (6) that the steady-state values of $\bar{P}_{m, \text { adi }}$ and $\overline{\dot{Q}}_{h, \text { adi }}$, denoted herewith as $\bar{P}_{m}(0)$ and $\bar{Q}_{h}(0)$ respectively, are directly proportional to the product of engine speed $\bar{\omega}_{m}$ and mean pressure $\bar{p}_{\text {mean }}$. In practice, due to thermal and frictional losses, $\bar{P}_{m}(0)$ and $\bar{Q}_{h}(0)$ will deviate from that calculated using (5) and (6). Steady-state losses can be categorized into three groups, based on the manner by which the losses vary with $\bar{\omega}_{m}$ and $\bar{p}_{\text {mean }}$ [16]. Table I summarizes the main characteristics and the proposed expressions in quantifying such losses. Thus, a new set of more accurate expressions for $\bar{P}_{m}(0)$ and $\bar{Q}_{h}(0)$ can be derived by subtracting the losses shown in Table I from the steady-state values $\bar{P}_{m \text {,adi }}(0)$ and $\dot{Q}_{h, \text { adi }}(0)$. Henceforth, the subscript "adi" shall be omitted from $\bar{P}_{m \text {,adi }}$ and $\overline{\dot{Q}}_{h \text {,adi }}$ to signify that the analysis to follow has included the losses. Thus,

$$
\begin{aligned}
& \bar{P}_{m}(0)=\bar{P}_{m, a d i}(0)-\Delta \bar{P}_{0}-\Delta \bar{P}_{1}-\Delta \bar{P}_{2} \\
& \quad=\left(\bar{K}_{m}-k_{11}\right) \bar{p}_{\text {mean }} \bar{\omega}_{m}-k_{00}-k_{10} \bar{p}_{\text {mean }}-k_{01} \bar{\omega}_{m} \\
& \quad-k_{02} \bar{\omega}_{m}^{2}-k_{12} \bar{p}_{\text {mean }} \bar{\omega}_{m}^{2} \\
& \overline{\dot{Q}}_{h}(0)=\overline{\dot{Q}}_{h, \text { adi }}(0)-\Delta \overline{\dot{Q}}_{0}-\Delta \overline{\dot{Q}}_{1} \\
& \quad=\left(\bar{K}_{h}-k_{11}^{\prime}\right) \bar{p}_{\text {mean }} \bar{\omega}_{m}-k_{00}^{\prime}-k_{10}^{\prime} \bar{p}_{\text {mean }}-k_{01}^{\prime} \bar{\omega}_{m} .
\end{aligned}
$$

Thus (7) and (8) show that $\bar{P}_{m}(0)$ and $\overline{\dot{Q}}_{h}(0)$ are multivariate polynomials (MP) of $\bar{p}_{\text {mean }}$ and $\bar{\omega}_{m}$. The coefficients $k_{i j}$ and $k_{i j}^{\prime}$ can be considered constant. Instead of estimating their values through thermodynamic and heat transfer analysis, a convenient approach is to determine the polynomial functions (7) and (8) which best-fit the engine steady-state performance maps of $\bar{P}_{m}(0)$ and $\bar{Q}_{h}(0)$ against $\bar{p}_{\text {mean }}$ and $\bar{\omega}_{m}$, obtained from experiments or that provided by the Stirling engine manufacturers. The general representations of output and input powers using MP model are thus

$$
\begin{aligned}
& \bar{P}_{m}(0)=\sum_{i=0}^{1} \sum_{j=0}^{2} b_{i j} \bar{p}_{\text {mean }}^{i} \bar{\omega}_{m}^{j} \\
& \bar{Q}_{h}(0)=\sum_{i=0}^{1} \sum_{j=0}^{1} a_{i j} \bar{p}_{\text {mean }}^{i} \bar{\omega}_{m}^{j}
\end{aligned}
$$

where $b_{i j}$ and $a_{i j}$ are the respective dimensionless MP coefficients. Second-order approximation is considered sufficiently accurate to represent the effect of losses around the operating state. By comparing (9) and (10) with (7) and (8) respectively, two new parameters $\hat{K}_{m}$ and $\hat{K}_{h}$ are defined and they will be used to replace respectively $\bar{K}_{m}$ and $\bar{K}_{h}$ in (5) and (6) of the ideal average adiabatic model, respectively

$$
\hat{K}_{m}=\sum_{i=0}^{1} \sum_{j=0}^{2} b_{i j} \bar{p}_{\text {mean }}^{i-1} \bar{\omega}_{m}^{j-1}, \hat{K}_{h}=\sum_{i=0}^{1} \sum_{j=0}^{1} a_{i j} \bar{p}_{\text {mean }}^{i-1} \bar{\omega}_{m}^{j-1} .
$$

The last row of Table I also shows typical values of the MP coefficients calculated using the data of a Stirling engine reported in [17]. The root-mean-square error between the calculated $\bar{P}_{m}(0)$ and $\bar{Q}_{h}(0)$ and those obtained in [17] for $\bar{p}_{\text {mean }}=0.33-1$ p.u. is less than $2.5 \%$. This indicates that the developed steady-state model is sufficiently accurate.

Also, from (9), at the nominal operating point $\bar{p}_{\text {mean }}=$ 1 p.u., $\bar{\omega}_{m}=1$ p.u., and $P_{m}(0)=1$ p.u., thus, 
TABLE I

SUMMARY OF MAJOR THERMAL AND MECHANICAL LOSSES OF THE STIRLING ENGINE [16]

\begin{tabular}{|c|c|c|c|}
\hline Type & Static thermal loss & Linear thermal loss & Friction effects \\
\hline $\begin{array}{l}\text { Causes } \\
\text { losses }\end{array}$ & $\begin{array}{l}\text { Conduction; shuttle heat transfer; } \\
\text { convection and radiation }\end{array}$ & Stack loss; hysteresis loss; imperfect regeneration & "Mechanical friction; Aerodynamic friction \\
\hline $\begin{array}{l}\text { Characteristics } \\
\text { of the losses }\end{array}$ & $\begin{array}{l}\text { on the temperatures and are inde- } \\
\text { pendent of the speed and pressure }\end{array}$ & Increase linearly as the speed or pressure increases & $\begin{array}{l}\text { Second or higher order relationship with the } \\
\text { engine speed, only affect the output power }\end{array}$ \\
\hline $\begin{array}{l}\text { Proposed } \\
\text { expressions }\end{array}$ & $\begin{array}{l}\Delta \bar{P}_{0}=k_{00} \\
\Delta \dot{Q}_{0}=k_{00}^{\prime}\end{array}$ & $\begin{array}{l}\Delta \bar{P}_{1}=k_{10} \bar{p}_{\text {mean }}+k_{01} \bar{\omega}_{m}+k_{11} \bar{p}_{\text {mean }} \bar{\omega}_{m} \\
\Delta \dot{Q}_{1}=k_{10}^{\prime} \bar{p}_{\text {mean }}+k_{01}^{\prime} \omega_{m}+k_{11}^{\prime} \bar{p}_{\text {mean }} \bar{\omega}_{m}\end{array}$ & $\Delta \bar{P}_{2}=k_{02} \bar{\omega}_{m}^{2}+k_{12} \bar{p}_{\text {mean }} \bar{\omega}_{m}^{2}$ \\
\hline $\begin{array}{l}\text { Typical MP } \\
\text { coefficients }\end{array}$ & \multicolumn{3}{|c|}{$\begin{array}{l}b_{00}=-k_{00}=-0.038, b_{10}=-k_{10}=-0.072, b_{01}=-k_{01}=0.055, b_{11}=K_{m}-k_{01}=1.21, b_{02}=-k_{02}=-0.026, \\
b_{12}=-k_{12}=-0.13, a_{00}=-k_{00}^{\prime}=0.048, a_{10}=-k_{10}^{\prime}=0.072, a_{01}=-k_{01}^{\prime}=0.214, a_{11}=\bar{K}_{h}-k_{01}^{\prime}=2.264\end{array}$} \\
\hline
\end{tabular}

$\sum_{i=0}^{1} \sum_{j=0}^{2} b_{i j}=1$. Dividing $\bar{P}_{m}(0)$ by $\bar{Q}_{h}(0)$ which is obtained from (10) yields

$$
\frac{\bar{P}_{m}(0)}{\overline{\dot{Q}}_{h}(0)}=\eta_{\mathrm{se}, N}=1 / \sum_{i=0}^{1} \sum_{j=0}^{1} a_{i j} .
$$

Thus, (12) allows the thermal efficiency $\eta_{\mathrm{se}, N}$ of the Stirling engine at the nominal operating state to be more accurately evaluated as $a_{i j}$ are known and the various losses have been accounted for.

\section{RECEIVER/ABSORBER TEMPERATURE CONTROL}

\section{A. Linearized Model for Temperature Controller Design}

Convert concentrator-receiver model described by (4) into its normalized form, viz.

$$
\bar{T}_{h}=\frac{K_{\mathrm{rec}}\left(K_{\mathrm{con}} \bar{I}(s)-\overline{\dot{Q}}_{h}(s)\right)+\bar{T}_{a}}{1+T_{\mathrm{rec}} s}
$$

where $T_{\text {rec }}=K_{r} / K_{L}, K_{\text {con }}=\eta_{\text {con }} A_{\text {con }} I_{\max } / P_{m, N}$, and $K_{\text {rec }}=P_{m, N} /\left(K_{L} T_{h, \max }\right)$. Fig. 1 shows the two major disturbances in the temperature control loop are the variations of $\bar{I}$ and $\bar{\omega}_{m}$, the latter would include the consequence of a disturbance in the external grid system. Consider a small deviation from an arbitrary steady-state operating point $\bar{p}_{\text {mean }}=\bar{p}_{0} \in\left[\bar{p}_{\min }, \bar{p}_{\text {max }}\right], \bar{T}_{h}=\bar{T}_{h 0} \in\left[\bar{T}_{h, \text { min }}, \bar{T}_{h, \text { max }}\right]$, and $\bar{\omega}_{m 0}=1$ p.u.. From (13), variations of $\bar{T}_{h}$ can be expressed as

$$
\Delta \bar{T}_{h}(s)=\frac{K_{\mathrm{rec}}\left(K_{\mathrm{con}} \Delta \bar{I}(s)-\Delta \overline{\dot{Q}}_{h}\right)}{1+T_{\mathrm{rec}} s}
$$

Using (6) and (11), $\Delta \overline{\dot{Q}}_{h}$ due to changes of $\Delta \bar{\omega}_{m}$ and $\Delta \bar{p}_{\text {mean }}$ can be expressed as

$$
\Delta \overline{\dot{Q}}_{h}=\frac{\partial \overline{\dot{Q}}_{h}}{\partial \bar{p}_{\text {mean }}} \Delta \bar{p}_{\text {mean }}+\frac{\partial \overline{\dot{Q}}_{h}}{\partial \bar{\omega}_{m}} \Delta \bar{\omega}_{m} .
$$

where the coefficients are

$$
\frac{\partial \overline{\dot{Q}}_{h}}{\partial \bar{p}_{\text {mean }}}=\left(a_{10}+a_{11}\right) \frac{1-T_{\mathrm{sel}} s}{1+T_{\mathrm{se} 2} s}, \quad \frac{\partial \overline{\dot{Q}}_{h}}{\partial \bar{\omega}_{m}}=a_{01}+a_{11} \bar{p}_{0} .
$$

Combining Fig. 2, (14), and (15), the linearized model of the Stirling engine for the receiver/absorber temperature control is obtained. It is illustrated in Fig. 3 where the relevant expressions used in deriving the model are also shown.

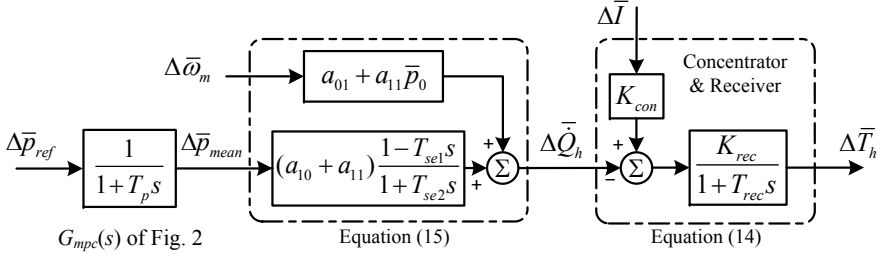

Fig. 3. Linearized plant model for the design of temperature control of the heat absorber in Stirling engine.

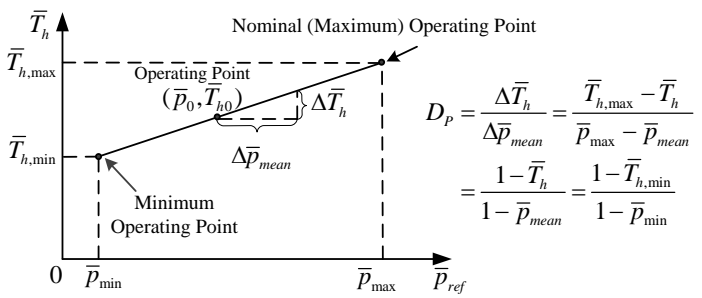

Fig. 4. Droop control characteristic of temperature vs. pressure.

\section{B. A New Temperature Control Scheme}

In the control of the receiver/absorber temperature in the Stirling engine, the average temperature on the absorber is conventionally measured using thermocouple. The pressure reference setting $\bar{p}_{\text {ref }}$ is often calculated based on empirical static temperature-pressure droop characteristic, such as that shown in Fig. 4 [6]. With the permanent droop $D_{P}$ as defined in the figure, thus $\bar{T}_{h}$ is not maintained constant over the whole range of the insolation level. This is equivalent to the introduction of a proportional controller with gain $1 / D_{P}$ into the temperature control system.

From Fig. 3, it can be seen that the plant parameters in the temperature control loop are independent of $\bar{T}_{h}$ and $\bar{p}_{\text {mean }}$ under constant $\bar{\omega}_{m}$ operation. Thus, the temperature controller can be tuned at an arbitrary operating point of $\bar{T}_{h}$ and $\bar{p}_{\text {mean }}$. It can be readily shown that the corresponding open-loop transfer function of the temperature control system is

$$
\frac{\Delta \bar{T}_{h}(s)}{\Delta \bar{T}_{h, \mathrm{ref}}(s)} \approx \frac{K_{\Sigma}\left(1-T_{\mathrm{sel}} s\right)}{D_{P}\left(1+T_{\Sigma} s\right)} .
$$

In arriving at (16), one makes use of the fact that $T_{\text {rec }} \gg T_{p}$ and $T_{\text {rec }} \gg T_{\mathrm{se} 2}$, and denotes $K_{\Sigma}=K_{\mathrm{rec}}\left(a_{10}+a_{11}\right), T_{\Sigma}=$ $T_{p}+T_{\mathrm{se} 2}+T_{\mathrm{rec}}$. Apply Hurwitz-Routh Stability Criteria on the resulting closed-loop transfer function, stable operation of 


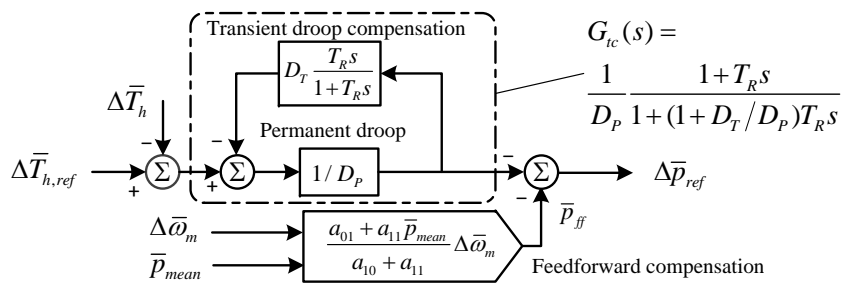

Fig. 5. New temperature controller with transient droop and feedforward compensation.

the temperature control scheme is guaranteed when

$$
D_{P}>K_{\Sigma} T_{\mathrm{se} 1} / T_{\Sigma}
$$

Due to the nonminimum phase nature of $G_{h}(s)$ as shown in (6), however, the change in $\bar{p}_{\text {mean }}$ will cause an initial $\bar{Q}_{h}$ change in a direction opposite to that sought. Thus, $\bar{T}_{h}$ will require a longer time to reach its new steady state following a sudden $\bar{I}$ or $\bar{\omega}_{m}$ variations. A solution to reduce the settling time is to increase $D_{P}$, but it will lead to an increase in the steady-state error in $\bar{T}_{h}$ and a significant reduction in the engine efficiency.

To overcome this problem, a transient droop compensation scheme is now proposed. The new temperature control scheme is shown in Fig. 5 in which $D_{T}$ denotes the temporary droop setting and $T_{R}$ is the reset time. From the transfer function of the proposed temperature controller $G_{\mathrm{tc}}(s)$ shown in Fig. 5, it can be readily shown that the equivalent droop is temporarily increased to $D_{P}+D_{T}$ at the initial stage of the transients. The range of $D_{P}$ for which closed-loop stability is guaranteed is

$$
D_{P}>\max \left\{\frac{K_{\Sigma} T_{\mathrm{se} 1}}{T_{\Sigma}} \frac{1}{1+\frac{D_{T}}{D_{P}}}, \frac{K_{\Sigma}\left(T_{\mathrm{se} 1}-T_{R}\right)}{T_{\Sigma}+\left(1+\frac{D_{T}}{D_{P}}\right) T_{R}}\right\} .
$$

It can be seen that $D_{P}$ determined from (18) is smaller than that obtained in (17). The proposed scheme provides lag compensation and leads to improved system stability.

\section{Feedforward Compensation During Speed Variations}

As can be seen from the above analysis, variations in the engine speed $\Delta \bar{\omega}_{m}$ would result in absorber temperature change. During normal operation, $\Delta \bar{\omega}_{m}$ tends to be small and the temperature control functions described in Section IV-B functions well. However, if $\Delta \bar{\omega}_{m}$ varies greatly during e.g. severe system disturbance condition, $\Delta \bar{\omega}_{m}$ needs to be compensated for. This can be achieved by generating a feedforward signal $\bar{p}_{\text {ff }}$ for $\Delta \bar{p}_{\text {ref. }}$. As reflected by the second term on the right-hand-side of (15) and using measured $\bar{\omega}_{m}$ and $\bar{p}_{\text {mean }} \cdot \bar{p}_{\mathrm{ff}}$ is given as

$$
\bar{p}_{\mathrm{ff}}=\frac{a_{01}+a_{11} \bar{p}_{0}}{a_{10}+a_{11} \bar{\omega}_{m 0}} \Delta \bar{\omega}_{m} \approx \frac{a_{01}+a_{11} \bar{p}_{\text {mean }}}{a_{10}+a_{11}} \Delta \bar{\omega}_{m} .
$$

The feedforward control is also featured in Fig. 5.

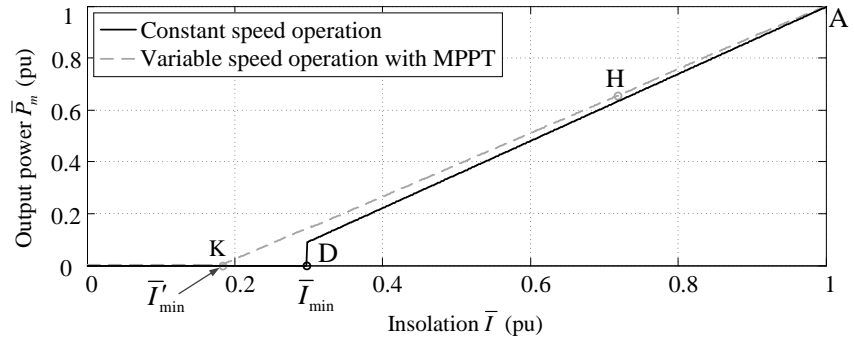

Fig. 6. $\bar{P}_{m}-\bar{I}$ relationship under constant speed and variable speed operation of the DS system.

\section{Relationship Between Steady-State Output POWER, SPEED AND INSOLATION LEVEL}

\section{A. Output Power Versus Insolation Under Constant Speed Operation}

In this section, steady-state operation of the DS system will be examined. The notation "(0)" will be omitted. As $\bar{T}_{h}$ can be effectively maintained nearly constant by the improved control scheme described in Section IV, the effect of $\Delta \bar{T}_{h}$ on the engine performance will not be included in the analysis. Substituting (10) and the expression of $D_{P}$ in Fig. 4 into (13), the steady-state relationship governing $\bar{p}_{\text {mean }}, \bar{I}$ and $\bar{\omega}_{m}$ is obtained

$$
\bar{p}_{\text {mean }}=\left(K_{\text {con }} \bar{I}-a_{01} \bar{\omega}_{m}-a_{00}^{\prime}\right) /\left(a_{11} \bar{\omega}_{m}+a_{10}^{\prime}\right)
$$

where $a_{00}^{\prime}=a_{00}+\left(1-\bar{T}_{a}\right)-D_{P} / K_{\text {rec }}$ and $a_{10}^{\prime}=a_{10}+$ $D_{P} / K_{\text {rec }}$. In practice however, $\bar{p}_{\text {mean }}$ must be higher than the minimum pressure $\bar{p}_{\min }$. For constant speed operation, thus (20) is only applicable above the minimum insolation level $\bar{I}_{\min }$ where $\bar{I}_{\min }$ is obtained by substituting $\bar{p}_{\min }$ into (20), i.e.,

$$
\bar{I}_{\text {min }}=\left[\left(a_{11} \bar{p}_{\min }+a_{01}\right) \bar{\omega}_{m}+a_{10}^{\prime} \bar{p}_{\min }+a_{00}^{\prime}\right] / K_{\text {con }} .
$$

Also, by substituting (20) into (9), the relationship between the steady-state output power $\bar{P}_{m}, \bar{\omega}_{m}$, and $\bar{I}$ can be obtained:

$$
\bar{P}_{m}=m_{1} \bar{I}+n_{1}
$$

where

$$
\begin{aligned}
m_{1} & =K_{\mathrm{con}}\left(b_{10}+b_{11} \bar{\omega}_{m}+b_{12} \bar{\omega}_{m}^{2}\right) /\left(a_{11} \bar{\omega}_{m}+a_{10}^{\prime}\right) \\
n_{1} & =b_{00}+b_{01} \bar{\omega}_{m}+b_{02} \bar{\omega}_{m}^{2}-m_{1}\left(a_{01} \bar{\omega}_{m}+a_{00}^{\prime}\right) / K_{\mathrm{con}} .
\end{aligned}
$$

For constant-speed operation with (say) $\bar{\omega}_{m}$ at the nominal speed of 1 p.u., from (22), $\bar{P}_{m}$ is seen to be linear with respect to $\bar{I}$. This is shown in Fig. 6 by the line A-D. If $\bar{I}$ is less than $\bar{I}_{\min }, \bar{T}_{h}$ will rise as the power balance cannot be maintained by reducing $\bar{p}_{\text {mean }}$ any further. $\bar{T}_{h}$ is then not controllable and may even exceed its maximum set value: the DS system is to shut down and the output power is zero.

If one ignores losses in the mechanical to electrical energy conversion process in generator, the linear $\bar{P}_{m}-\bar{I}$ characteristic is similar to DS system output electrical power vs. insolation relationship derived from the linear interpolation of the experimental data shown in [18]. The present approach is, however, advantageous in that it provides a direct means in deriving the linear relationship (22) based on the proposed MP model. Hence, the approach is particularly useful during the feasibility evaluation or planning stage of specific DS power plant. 


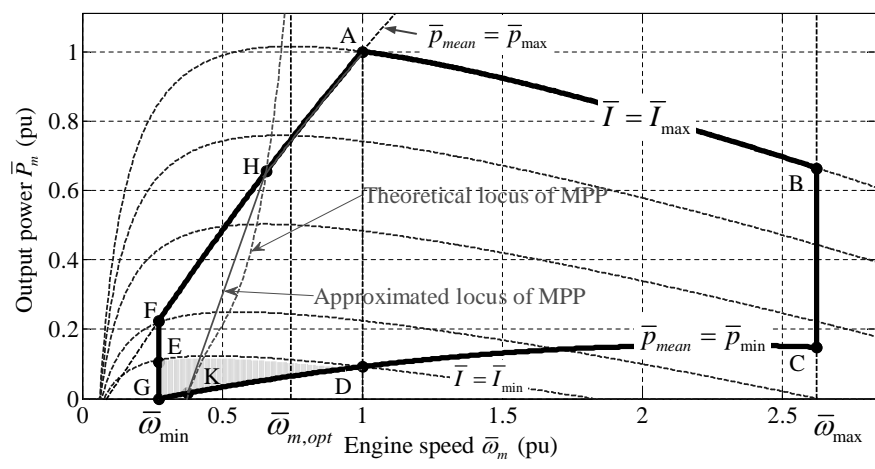

Fig. 7. Steady-state feasible operating area of DS system.

\section{B. Feasible Operating Regime Under Variable Speed Opera- tion}

Equation (20) shows explicitly how steady-state $\bar{p}_{\text {mean }}, \bar{\omega}_{m}$ and $\bar{I}$ are related. As shown in (7) and (9), $\bar{p}_{\text {mean }}$ and $\bar{\omega}_{m}$ are the two important variables that govern the $\bar{P}_{m}$. The potential of controlling $\bar{P}_{m}(0)$ through the manipulation of $\bar{\omega}_{m}$ shall now be examined. Using (7) and (22), a family of typical $\bar{P}_{m}-\bar{\omega}_{m}$ curves at different insolation levels is depicted in Fig. 7. Note that at each of the constant- $I$ curves, there is a corresponding maximum $\bar{P}_{m}$. Also each point on the curve has the corresponding $\bar{p}_{\text {mean }}$, although $\bar{p}_{\text {mean }}$ has not been explicitly indicated on the figure.

Operation of the DS system is limited by several practical constraints placed on $\bar{p}_{\text {mean }}, \bar{\omega}_{m}$ and $\bar{I}$. These limits define the feasible operating boundary A-B-C-G-F-A shown on Fig. 7. The various sectors of the boundary are:

- A-B: applies due to the maximum insolation $\bar{I}$;

- B-C: dictates by the maximum engine speed $\bar{\omega}_{\max }$;

- $\mathrm{C}-\mathrm{G}$ : pertains to the minimum mean pressure $\bar{p}_{\min }$;

- G-F: governs by the minimum engine speed $\bar{\omega}_{\min }$;

- F-A: sets by the maximum mean pressure $\bar{p}_{\text {max }}$.

The boundary ABCGFA prescribes the steady-state feasible operating regime of the DS system. The boundaries F-A and $\mathrm{C}-\mathrm{G}$, corresponding to the engine operating under the maximum and minimum mean pressure respectively, can be derived by setting $\bar{p}_{\text {mean }}=\bar{p}_{\text {max }}$ and $\bar{p}_{\text {mean }}=\bar{p}_{\text {min }}$ in (9) for the speed range $\bar{\omega}_{\min } \leq \bar{\omega}_{m} \leq \bar{\omega}_{\max }$.

\section{Variable speed operation and maximum power harness}

Fig. 6 shows that for the constant-speed operation, there will be a minimum insolation level $\bar{I}_{\text {min }}$ below which power generation is not possible. The reason for this has been explained in Section V-A. Suppose the engine operates at the nominal speed $\bar{\omega}_{m}$ of 1 p.u. The engine operating state at the minimum insolation level will then correspond to the point $\mathrm{D}$ in Fig. 7 where $\bar{I}_{\text {min }}$ is obtained using (21) and $\bar{p}_{\text {mean }}=\bar{p}_{\text {min }}$. As $\bar{I}$ increases and maintaining $\bar{\omega}_{m}$ constant at 1 p.u., the operating state moves from $\mathrm{D}$ toward A where $\bar{I}=\bar{I}_{\max }$. The constant speed operation is therefore described by the line D-A. On the other hand, if the DS system is able to operate at variable speed and by reducing $\bar{\omega}_{m}$ to below 1 p.u., it is still feasible to operate the DS system in the shaded area
E-D-G-E where the insolation level is lower than $\bar{I}_{\min }$, the minimum insolation level determined under the constant speed mode. The corresponding minimum speed $\bar{\omega}_{m}$ at point $\mathrm{G}$ can be calculated by substituting $\bar{P}_{m}=0$ and $\bar{p}_{\text {mean }}=\bar{p}_{\text {min }}$ into (9). Then using (20), the minimum insolation level $\bar{I}_{\min }^{\prime}$ under variable-speed operation can be readily shown to be

$$
\bar{I}_{\text {min }}^{\prime}=\left[\bar{p}_{\text {min }}\left(a_{11} \bar{\omega}_{\text {min }}+a_{10}^{\prime}\right)+a_{01} \bar{\omega}_{\text {min }}+a_{00}^{\prime}\right] / K_{\text {con }}
$$

The nominal operating speed of the DS system is often selected to be at the maximum thermal efficiency point at maximum insolation. This is because this operating state can be easily found from the specifications or experimental data of the Stirling engine. However, Fig. 7 shows that the Stirling engine is not harnessing the maximum power at the nominal speed. The theoretical maximum power point (MPP) locus could be obtained by setting $\partial \bar{P}_{m} / \partial \bar{\omega}_{m}=0$ in (22), but this locus is a complex nonlinear equation. Instead, an approximate expression of the MPP locus can be derived by firstly, ignoring the terms containing the small-value coefficients $b_{00}, b_{01}, b_{02}$, and $a_{10}^{\prime}$ in (22). The approximate expression of $\bar{P}_{m}$ is

$$
\bar{P}_{m}=\frac{\left(b_{10}+b_{11} \bar{\omega}_{m}+b_{12} \bar{\omega}_{m}^{2}\right)}{a_{11} \bar{\omega}_{m}}\left(K_{\mathrm{con}} \bar{I}-a_{01} \bar{\omega}_{m}-a_{10}^{\prime}\right) \text {. }
$$

At high insolation level, $K_{\text {con }} \bar{I} \gg a_{01} \bar{\omega}_{m}+a_{10}^{\prime}$. The optimal speed $\bar{\omega}_{m, \text { opt }}$ by which maximum power harness occurs can be obtained by setting $\partial \bar{P}_{m} /\left.\partial \bar{\omega}_{m}\right|_{\bar{\omega}_{m}=\bar{\omega}_{m, \text { opt }}}=0$, whence

$$
\bar{\omega}_{m, \mathrm{opt}} \approx \sqrt{b_{10} / b_{12}} .
$$

Operation at constant speed $\bar{\omega}_{m, \text { opt }}$ is represented by the vertical line to the left of the nominal constant speed operating line A-D in in Fig. 7. The theoretical MPP locus is also shown there. In practice, due to the maximum pressure limit the theoretical MPP is not achievable above the point $\mathrm{H}$. The achievable maximum power is governed by the curve $\mathrm{H}-\mathrm{A}$ when $\bar{p}_{\text {mean }}=\bar{p}_{\text {max }}$. As $b_{12}<b_{10}<0$ and as $\bar{I}$ decreases, the MPP locus deviates increasingly from the vertical line A-D as the condition $K_{\text {con }} \bar{I} \gg a_{01} \bar{\omega}_{m}+a_{10}^{\prime}$ becomes less and less valid. At insolation level below that corresponding to that at point $\mathrm{H}$, the straight line $\mathrm{H}-\mathrm{K}$ can be used to approximate the MPP locus instead. $\mathrm{H}-\mathrm{K}$ is of the form

$$
\bar{P}_{m} \approx c \cdot \bar{\omega}_{m}+d \text {. }
$$

Equation (26) can be used to advantage in the design of a speed control strategy to achieve maximum power harness.

The overall $\bar{P}_{m}$ vs $\bar{I}$ MPP curve A-H-K under variable speed operation is also shown in Fig. 6. Clearly the amount of energy extracted under MPP depends on the characteristics of the $\bar{P}_{m}-\bar{\omega}_{m}$ curve of the Stirling engine and the selection of the nominal value of $\bar{\omega}_{m}$. If the nominal speed for the constant speed operation is much above $\bar{\omega}_{m, \mathrm{opt}}$, the variable speed operation of the DS system can be expected to be able to extract much more energy than that under constant speed operation.

\section{ILluStRATIVE EXAMPLE}

\section{A. System Configuration}

Consider a $25-\mathrm{kW}$ DS system connected to a large grid via a $480-\mathrm{V} / 22-\mathrm{kV}$ step-up transformer and $20-\mathrm{km}$ distribution 


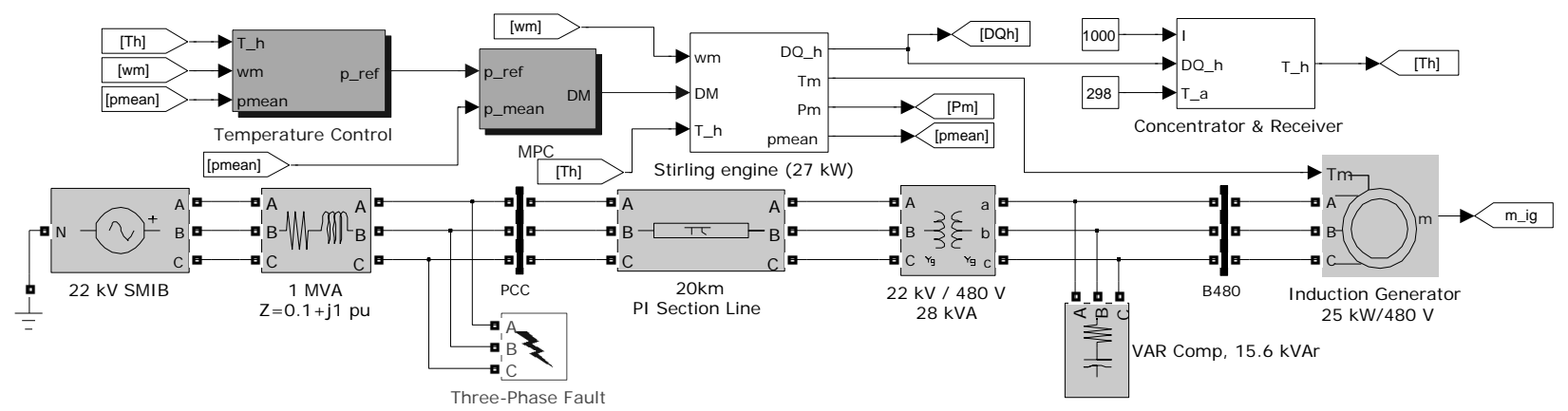

Fig. 8. Simulink model of DS solar-thermal power plant and grid system.

line. The short-circuit level at the $22-\mathrm{kV}$ connection point is assumed to be $1 \mathrm{MVA}$, yielding an equivalent system impedance of $0.1+j 1$ pu on 1-MVA base. The Stirling engine is connected to a $25-\mathrm{kW}$ induction generator (of 2 pole pairs). A 15.6-kVAr static capacitor bank is connected at the terminal of the induction generator for reactive power compensation purpose. The parameters of the DS system are: $\eta_{\text {con }}=0.88, A_{\text {con }}=87.7 \mathrm{~m}^{2}, K_{r}=200, K_{L}=14.83$, $T_{a}=298 \mathrm{~K}, K_{v}=1.0, T_{v}=0.02 \mathrm{~s}, V_{\mathrm{sw}}=95 \mathrm{~cm}^{3}$, $V_{\mathrm{cl}}=10 \mathrm{~cm}^{3}, V_{h}=33.08 \mathrm{~cm}^{3}, \theta=0.89 \pi \mathrm{rad}$, and $b=0.2$. Nominal parameters: $p_{\max }=20 \mathrm{MPa}, p_{\min }=2 \mathrm{MPa}$, $T_{h, \text { max }}=1033 \mathrm{~K}, I_{\max }=1000 \mathrm{~W} / \mathrm{m}^{2}, P_{m, N}=27 \mathrm{~kW}$, and $\omega_{m, N}=190.63 \mathrm{rad} / \mathrm{s}$. These parameters were obtained from [12] and [19]. The model of the power system, including that of the DS system, was established in MATLAB/Simulink and is illustrated in Fig. 8.

\section{B. Comparison of Ideal and Average-Value Adiabatic Models}

In this section, the purpose is to show the comparison between the results obtained using the ideal adiabatic model with that obtained using the proposed average-value adiabatic model. The disturbance is an ON-OFF three-cycle three-phase to ground fault applied at the $22-\mathrm{kV}$ connecting point. As insolation level is not expected to change significantly over the fault duration, $\bar{I}$ can be considered constant over the study period.

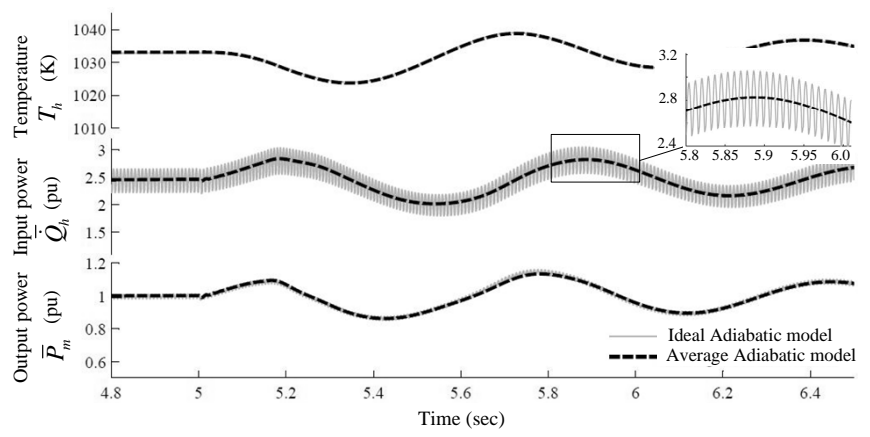

Fig. 9. Comparison between the simulation results using the ideal adiabatic model and the average-value adiabatic model.

The simulation results based on the ideal and average-value adiabatic models are shown in Fig. 9. It can be seen that using the average-value adiabatic model, only the average values of the input and output powers of the Stirling engine are evaluated. The high-frequency components (at twice the power frequency) caused by the engine piston motion are not represented. The average values reflect accurately the responses in terms of the output power and temperature. The corresponding step-size used was $50 \mu$ s and required $33.1 \mathrm{~s}$ to complete. This step-size is suitable for most type of power system electromagnetic transient studies. Using the ideal adiabatic model, however, it required a $2-\mu$ s step-size and the simulation time was much higher at $333.2 \mathrm{~s}$. Thus using the average-value adiabatic model can speed up the simulation without greatly compromising the accuracy required in the study of power system dynamics.

\section{Temperature Controller Design}

The relevant parameters for the absorber temperature control design can be calculated using the corresponding equations in Section IV: $K_{\text {con }}=2.865, K_{\text {rec }}=1.756, T_{\text {rec }}=13.44 \mathrm{~s}$, $T_{p}=0.056 \mathrm{~s}, T_{\mathrm{se} 1} \approx 0.11 \mathrm{~s}$ at $\omega_{m}=1$ p.u., and $T_{\mathrm{se} 2}=0.03 \mathrm{~s}$. The minimum $D_{P}$ calculated from (17) for the conventional temperature control system is 0.027 , and its corresponding minimum temperature limit $T_{h \text {,min }}$ must be less than $1008 \mathrm{~K}$. In practice, $T_{h, \text { min }}$ is selected as $993 \mathrm{~K}\left(720{ }^{\circ} \mathrm{C}\right)$ using the droop controller, to guarantee stability of the system. However, from Bode analysis, the corresponding phase margin is only $8.1^{\circ}$ and the cut-off frequency $\left(\omega_{c}\right)$ is $8.4 \mathrm{rad} / \mathrm{s}$. When a large disturbance occurs, it will require a relatively long time for the temperature and output power to return to their steady states.

Using the transient droop compensation, in order to enhance the transient response, the corresponding break frequency of the compensator is selected to be higher than $1 / T_{\text {rec }}$ and lower than $\omega_{c}$, i.e., $1 / \omega_{c}<T_{R}<\left(1+D_{T} / D_{P}\right) T_{R}<T_{\text {rec }}$. By selecting $T_{R}=0.5 \mathrm{~s}$ and $D_{T}=D_{P}$, the new phase margin is $37.1^{\circ}$ which results in a much improved design over the conventional controller.

This expected improvement could be verified by studying the performance of the proposed temperature control scheme under rapid insolation variation condition. Typically, a rate of change of $I$ of $30 \mathrm{~W} /\left(\mathrm{m}^{2} \cdot \mathrm{s}\right)$ is considered high in photovoltaic system study [20]. Fig. 10 shows the results of a study in which $I$ has been ramped down and then up at a rate of $100 \mathrm{~W} /\left(\mathrm{m}^{2} \cdot \mathrm{s}\right)$ or 0.1 p.u./s. Even at such a rapid change, the proposed temperature controller with transient droop and feedforward compensation is able to maintain the absorber 


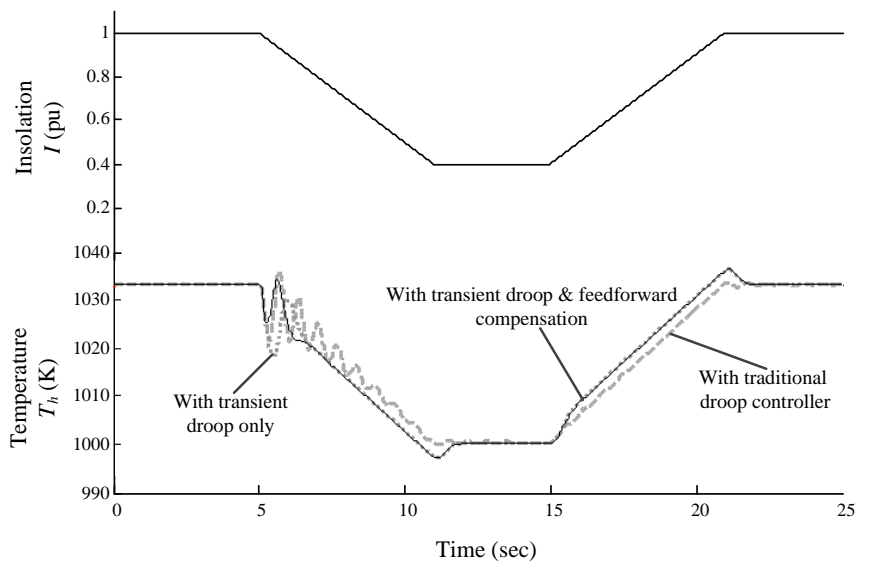

Fig. 10. Performance of the temperature controller under insolation variation.

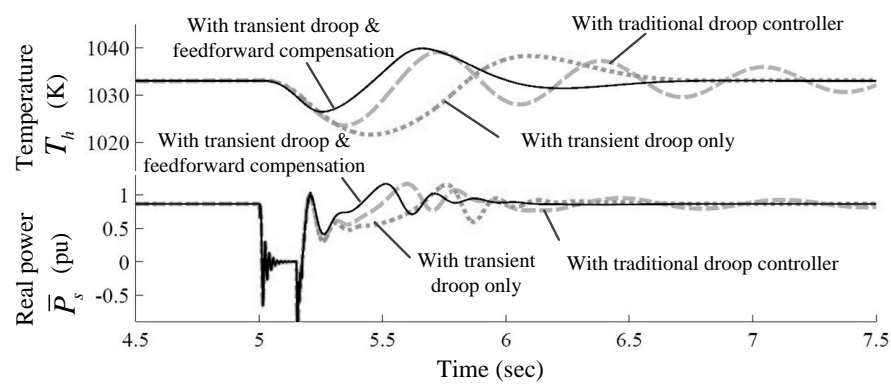

Fig. 11. Comparison between the simulation results obtained using the conventional droop and improved temperature controllers.

temperature to within an acceptable range and with negligible over- and under-shoots.

The proposed design is further tested under the grid-fault condition considered earlier. The responses of the DS system based on the conventional droop and the proposed transient droop reduction controllers are compared in Fig. 11. There are persistent power oscillations after the fault clearance in the case of using the conventional droop controller. Similar phenomenon is also observed in the simulation result shown in [19]. Such power oscillations are undesirable if large-scale DS system is incorporated into the power grid. By introducing the transient droop compensation, the transients in the output power and temperature excursions are much rapidly subdued. Further improvement is seen with the addition of the proposed feedforward compensation.

\section{CONCLUSION}

Existing Stirling engine models are unsuitable for use in grid-related studies and instead, an average adiabatic model of the engine has been proposed. The proposed model also takes into account the effects of steady-state thermal losses and demands much less computation time. The model also shows the engine exhibits nonminimum phase behavior and is able to capture those dynamics essential for power system study.

Based on the developed model, an improved temperature controller with transient droop reduction and feedforward compensation has been proposed. This new temperature controller is effective in reducing the temperature excursions following a disturbance. It also leads to improved damping in the output power of the DS solar-thermal power plant.

Furthermore, based on the steady-state analysis of the DS system, feasible operating area of the power plant has also been obtained. It is shown that to maximize the harness of the solar energy, it requires the DS system to operate under a variable speed mode.

\section{APPENDIX}

Derivation of the Average-Value Adiabatic Model

The original ideal adiabatic analysis of Stirling engine can be found in [12], while a revised model considering the variation of $M$ and $T_{h}$ was derived in [19]. Relevant equations needed for deriving the simplified average-value model are:

Mass Flow Equations:

$$
\begin{aligned}
& \mathrm{D} m_{k}=m_{k}\left(\mathrm{D} p / p-\mathrm{D} T_{k} / T_{k}\right) \\
& \mathrm{D} m_{r}=m_{r}\left(\mathrm{D} p / p-\mathrm{D} T_{r} / T_{r}\right) \\
& \mathrm{D} m_{h}=m_{h}\left(\mathrm{D} p / p-\mathrm{D} T_{h} / T_{h}\right) \\
& g A_{\mathrm{he}}=g A_{\mathrm{rh}}-\mathrm{D} m_{h}=\mathrm{D} m_{e}=\frac{p \mathrm{D} v_{e}+v_{e} \mathrm{D} p / \gamma}{R T_{\mathrm{he}}} \\
& \mathrm{D} M=\mathrm{D} m_{c}+\mathrm{D} m_{k}+\mathrm{D} m_{r}+\mathrm{D} m_{h}+\mathrm{D} m_{e}
\end{aligned}
$$

Heat and Work Equations:

$$
\begin{gathered}
\mathrm{D} Q_{h}=V_{h} c_{v} \mathrm{D} p / R-c_{p}\left(T_{\mathrm{rh}} g A_{\mathrm{rh}}-T_{\mathrm{he}} g A_{\mathrm{he}}\right) \\
\mathrm{D} W=p\left(\mathrm{D} v_{c}+\mathrm{D} v_{e}\right)
\end{gathered}
$$

Volume Equations:

$$
\begin{aligned}
v_{e} & =V_{d}+0.5 V_{\mathrm{sw}} \cos \left(\phi-\alpha_{c}-\pi / 2\right) \\
\mathrm{D} v_{e} & =-0.5 V_{\mathrm{sw}} \sin \left(\phi-\alpha_{c}-\pi / 2\right)
\end{aligned}
$$

where $V_{d}=V_{\mathrm{cl}}+0.5 V_{\mathrm{sw}}$ is the volume of the working space when the piston is in the oscillation center. Assumptions for double-acting kinematic engine include (a) Uniform temperature distribution in the heater head; (b) Variation of the total mass due to the action of pressure control system in each cylinder is the same; (c) The variation of temperature of the working gas does not affect the performance of the engine in the normal operating conditions. Substituting (29) into (30) and considering $\mathrm{D} T_{h} / T_{h} \ll \mathrm{D} p / p$, it can be shown that

$$
g A_{\mathrm{rh}} \approx \mathrm{D} m_{e}+m_{h} \mathrm{D} p / p=\mathrm{D} m_{e}+\left[V_{h} /\left(R T_{h}\right)\right] \mathrm{D} p
$$

Substituting (36) into (32) and assuming $T_{\mathrm{rh}}=T_{h}$, we have

$$
\mathrm{D} Q_{h}=-V_{h} \mathrm{D} p-c_{p} T_{h} \mathrm{D} m_{e}+\left(c_{p} / R\right)\left(p \mathrm{D} v_{e}+v_{e} \mathrm{D} p / \gamma\right)
$$

Now consider four cylinders in the double-acting kinematic configuration. From (37), The total heat absorbed is

$$
\begin{aligned}
\mathrm{D} Q_{h, \text { total }} & =\sum_{i=1}^{4} \mathrm{D} Q_{h, i}=-V_{h} \overbrace{\sum_{i=1}^{4} \mathrm{D} p_{i}}^{\mathrm{D}}-c_{p} T_{h} \overbrace{\sum_{i=1}^{4} \mathrm{D} m_{e, i}}^{\text {2 }} \\
& +\frac{c_{p}}{R} \overbrace{\sum_{i=1}^{4}\left(p_{i} \mathrm{D} v_{e, i}+v_{e, i} \frac{\mathrm{D} p_{i}}{\gamma}\right)}^{(38)}
\end{aligned}
$$


where the subscript $i=1-4$ indicates the cylinder number.

The original pressure equation in the ideal adiabatic model is quite complex. However, from observation of the waveforms $p_{i}$, it can be seen that it is quite sinusoidal. Ignore the second and higher orders components, denote the magnitude and phase of fundamental component of $p_{i}$ as $\Delta p_{i}$ and $\theta$, and the average value of $p_{i}$ as $\bar{p}_{i}$. As shown in [12], $\Delta p_{i}$ is proportional to $\bar{p}_{i}$. Therefore $p_{i}$ can be expressed as

$$
p_{i} \approx\left[1+b \cos \left(\phi-\alpha_{c, i}-\theta\right)\right] \bar{p}_{i}
$$

In (39), $b$ and $\theta$ are assumed to be constant and can be calculated from the dimension and temperature of the working gas. Typically $b$ is about 0.2 and $\theta$ is between $\pi / 2$ and $\pi$.

Differentiating (39) with respect to crank angle $\phi$, thus

$$
\mathrm{D} p_{i}=-b \sin \left(\phi-\theta_{1}\right) \bar{p}_{i}+\left[1+b \cos \left(\phi-\theta_{1}\right)\right] \mathrm{D} \bar{p}_{i}
$$

where $\theta_{1}=\theta+\alpha_{c, i}$. With (34), (35), (39), and (40), thus

$$
\begin{gathered}
p_{i} \mathrm{D} v_{e, i}=\left(V_{1}+\tilde{V}_{1, i}\right) \bar{p}_{i} \\
v_{e, i} \mathrm{D} p_{i}=\left(V_{2}+\tilde{V}_{2, i}\right) \bar{p}_{i}+\left(V_{3}+\tilde{V}_{3, i}\right) \mathrm{D} \bar{p}_{i}
\end{gathered}
$$

where $V_{1}=-V_{2}=-0.25 V_{\mathrm{sw}} b \cos \theta$ and $V_{3}=V_{d}+$ $0.25 V_{\mathrm{sw}} b \sin \theta . \tilde{V}_{1, i}, \tilde{V}_{2, i}$, and $\tilde{V}_{3, i}$ can be expressed as linear combination of $\sin \phi, \cos \phi, \sin 2 \phi$, and $\cos 2 \phi$. As the adjacent piston has $\pi / 2$ phase angle difference, it can be shown that

$$
\sum_{i=1}^{4} \tilde{V}_{1, i}=\sum_{i=1}^{4} \tilde{V}_{2, i}=\sum_{i=1}^{4} \tilde{V}_{3, i}=0
$$

Thus, using (41)-(43), and assuming $\bar{p}_{i}=p_{\text {mean }}$, one can evaluate (3) in (38) as

$$
\sum_{i=1}^{4}\left(p_{i} \mathrm{D} v_{e, i}+v_{e, i} \frac{\mathrm{D} p_{i}}{\gamma}\right)=\frac{4 R}{c_{p}} V_{1} p_{\text {mean }}+\frac{4 c_{v}}{c_{p}} V_{3} \mathrm{D} p_{\text {mean }}
$$

Using (40), one can readily obtain (1) in (38) as

$$
\sum_{i=1}^{4} \mathrm{D} p_{i}=4 \mathrm{D} p_{\text {mean }}
$$

and (2) in (38) can be estimated by substituting (27)-(29) into (31) and ignoring the temperature variation terms, thus

$$
\begin{aligned}
& \sum_{i=1}^{4} \mathrm{D} m_{c, i}+\sum_{i=1}^{4} \mathrm{D} m_{e, i}= \\
& \quad \frac{4}{K_{p}} \mathrm{D} p_{\text {mean }}-\frac{4}{R}\left(\frac{V_{k}}{T_{k}}+\frac{V_{r}}{T_{r}}+\frac{V_{h}}{T_{h}}\right) \mathrm{D} p_{\text {mean }}
\end{aligned}
$$

For the double-acting kinematic configuration engine, $K_{p}$ can be expressed as [4]

$$
K_{p}=R /\left(K \sqrt{1-B^{2}}\right)
$$

where $B=V_{\text {sw }} \sqrt{T_{h}^{2}+T_{k}^{2}} /\left(2 T_{h} T_{k} K\right), K=V_{k} / T_{k}+V_{r} / T_{r}+$ $V_{h} / T_{h}+V_{d}\left(T_{h}+T_{k}\right) /\left(T_{h} T_{k}\right)$.
Next, using the ideal gas equation, the variation of the working gas mass in the expansion space is

$$
\begin{aligned}
\mathrm{D} m_{e, i} & =\mathrm{D}\left(\frac{p_{i} v_{e, i}}{R T_{e, i}}\right)=\frac{\mathrm{D} v_{e, i}+v_{e, i}\left(\mathrm{D} p_{i} / p_{i}-\mathrm{D} T_{e, i} / T_{e, i}\right)}{R T_{e, i} / p_{i}} \\
& \approx\left(p_{i} \mathrm{D} v_{e, i}+v_{e, i} \mathrm{D} p_{i}\right) / R
\end{aligned}
$$

In obtaining (48), one makes the assumptions that $\mathrm{D} T_{e, i} / T_{e, i} \ll \mathrm{D} p_{i} / p_{i}$, and $T_{e, i}$ is equal to the average temperature $\bar{T}_{e}$ in the expansion space. Substituting (41) and (42) into (48) and considering (43), one obtains

$$
\sum_{i=1}^{4} \mathrm{D} m_{e, i}=4 V_{3} \mathrm{D} \bar{p}_{i} /\left(R \bar{T}_{e}\right)
$$

Similarly, it can be derived that

$$
\sum_{i=1}^{4} \mathrm{D} m_{c, i}=4 V_{4} \mathrm{D} \bar{p}_{i} /\left(R \bar{T}_{c}\right)
$$

where $V_{4}=V_{d}+0.25 V_{\mathrm{sw}} b \cos \theta$. The ratio of (49) and (50) is

$$
\sum_{i=1}^{4} \mathrm{D} m_{c, i} / \sum_{i=1}^{4} \mathrm{D} m_{e, i}=\frac{V_{3} \bar{T}_{e}}{V_{4} \bar{T}_{c}} \approx \frac{T_{h}}{T_{k}}
$$

Solving (46) and (51), (2) of (38) becomes,

$$
\sum_{i=1}^{4} \mathrm{D} m_{e, i}=4 \kappa \mathrm{D} p_{\text {mean }}
$$

where

$$
\kappa=\frac{T_{k}}{T_{h}+T_{k}}\left[\frac{1}{K_{p}}-\frac{1}{R}\left(\frac{V_{k}}{T_{k}}+\frac{V_{r}}{T_{r}}+\frac{V_{h}}{T_{h}}\right)\right]
$$

Substituting (44), (45), and (52) into (38), therefore

$$
\mathrm{D} Q_{h, \text { total }}=4 V_{1} p_{\text {mean }}+4 V_{5} \mathrm{D} p_{\text {mean }}
$$

where $V_{5}=-c_{p} T_{h} \kappa-V_{h}+c_{v} V_{3} / R$. Substituting (47) and (53) into the expression of $V_{5}$ and considering $B \ll 1$, thus

$$
V_{5} \approx-\left(V_{d}+V_{h}\right)+0.25 b \sin \theta V_{\mathrm{sw}} /(\gamma-1)
$$

In (55), as $b>0, \sin \theta<0$, and $\gamma>1$, thus $V_{5}<0$. Convert (54) into $s$-domain representation, thus

$$
\dot{Q}_{h, \text { total }}(s) / p_{\text {mean }}(s)=K_{h} \omega_{m}\left(1-T_{\text {se1 }} s\right)
$$

where $K_{h}=4 V_{1}$ and $T_{\mathrm{se} 1}=-V_{5} /\left(V_{1} \omega_{m}\right)$.

The total absorbed heat by the four cylinders still contains ripple. To obtain the average value $\dot{Q}_{h \text {,adi }}(s)$, a first-order lowpass filter can be used

$$
\dot{Q}_{h, \text { adi }}(s) / \dot{Q}_{h, \text { total }}(s)=1 /\left(1+T_{\mathrm{se} 2} s\right)
$$

Using (56) and (57) and through normalization, (6) is thus obtained, where $\bar{K}_{h}=K_{h} p_{\max } \omega_{m, N} / P_{m, N}$.

Similarly, by evaluating the summation of (33), (5) is derived, where $K_{m}=\sqrt{2} b \sin (\theta-0.75 \pi) V_{\text {sw }}$ and $\bar{K}_{m}=$ $K_{m} p_{\max } \omega_{m, N} / P_{m, N}$. 


\section{REFERENCES}

[1] T. Mancini, P. Heller, B. Butler, B. Osborn, W. Schiel, V. Goldberg, R. Buck, R. Diver, C. Andraka, and J. Moreno, "Dish-Stirling systems: An overview of development and status," ASME J. Solar Energy Eng., vol. 125 , no. 2, pp. 135-151, May 2003.

[2] Y. Bravo, M. Carvalho, L. M. Serra, C. Monn, S. Alonso, F. Moreno, and M. Muoz, "Environmental evaluation of dish-Stirling technology for power generation," Solar Energy, vol. 86, no. 9, pp. 2811-2825, Sep. 2012.

[3] D. Howard and R. G. Harley, "Modeling of dish-Stirling solar thermal power generation," in Proc. IEEE Power Energy Soc. Gen. Meeting, Minneapolis, MN, Jul. 2010, pp. 1-7.

[4] D. F. Howard, L. Jiaqi, and R. G. Harley, "Control of receiver temperature and shaft speed in dish-Stirling solar power plants to meet grid integration requirements," in IEEE Energy Convers. Congress Expo., Atlanta, GA, Sep. 2010, pp. 398-405.

[5] D. Santos-Martin, J. Alonso-Martinez, J. Eloy-Garcia, and S. Arnalte, "Solar dish-Stirling system optimisation with a doubly fed induction generator,' IET Renew. Power Gen., vol. 6, no. 4, pp. 276-288, Jul. 2012.

[6] S. Almstrom, C. Bratt, and H. Neiving, "Control systems for United Stirling 4-95 engine in solar application," in Proc. Intersoc. Energy Convers. Eng. Conf., Atlanta, GA, Aug. 1981.

[7] C. H. Cheng, H. S. Yang, B. Y. Jhou, Y. C. Chen, and Y. J. Wang, "Dynamic simulation of thermal-lag Stirling engines," Appl. Energy, vol. 108, pp. 466-476, Aug. 2013.

[8] Q. Yang, E. Luo, W. Dai, and G. Yu, "Thermoacoustic model of a modified free piston Stirling engine with a thermal buffer tube," Appl. Energy, vol. 90, no. 1, pp. 266-270, Feb. 2012.

[9] J. Ruelas, N. Velzquez, and J. Cerezo, "A mathematical model to develop a Scheffler-type solar concentrator coupled with a Stirling engine," Appl. Energy, vol. 101, pp. 253-260, Jan. 2013.

[10] A. Organ and T. Finkelstein, Thermodynamics and Gas Dynamics of the Stirling Cycle Machine. Cambridge University Press, 2010.

[11] Y. Timoumi, I. Tlili, and S. Ben Nasrallah, "Design and performance optimization of GPU-3 Stirling engines," Energy, vol. 33, no. 7, pp. 1100-1114, Jul. 2008.

[12] I. Urieli and D. Berchowitz, Stirling cycle engine analysis. Bristol, U.K.: A. Hilger, 1984.

[13] F. Nepveu, A. Ferriere, and F. Bataille, "Thermal model of a dish/Stirling systems," Solar Energy, vol. 83, no. 1, pp. 81-89, Jan. 2009.

[14] K. O. Lund, "A direct-heating energy-storage receiver for dish-Stirling solar energy systems," ASME J. Solar Energy Eng., vol. 118, no. 1, pp. 15-19, Feb. 1996.

[15] D. G. Thombare and S. K. Verma, "Technological development in the Stirling cycle engines," Renew. Sustain. Energy Rev., vol. 12, no. 1, pp. 1-38, Jan. 2008.
[16] G. Walker, Stirling engines. Clarendon Press, 1980.

[17] W. D. Ernst and R. K. Shaltens, "Automotive Stirling engine development project," U.S. Dept. of Energy, Tech. Rep. DOE/NASA/0032-34, 1997.

[18] W. B. Stine, "Experimentally validated long-term energy production prediction model for solar dish/Stirling electric generating systems," in Proc. Intersoc. Energy Convers. Eng. Conf., New York, NY, 1995, pp. 491-496.

[19] D. Howard, "Modeling, simulatiom, and analysis of grid connected dishStirling solar power plants,' Master's thesis, Sch. Elect. Comput. Eng., Georgia Inst. Technol., 2010.

[20] S. B. Kjaer, "Evaluation of the "hill climbing" and the "incremental conductance" maximum power point trackers for photovoltaic power systems," IEEE Trans. Energy Convers., vol. 27, no. 4, pp. 922-929, Dec. 2012.

Yang Li (S'11) received the B.E. degree in electrical engineering from Wuhan University, Wuhan, China, in 2007, and the M.Sc. degree in power engineering from Nanyang Technological University, Singapore, in 2008 where he is currently working toward the Ph.D. degree.

His research interests include solar thermal power generation, renewable energy, and energy storage systems.

San Shing Choi (M'03-SM'07) received the B.E. and Ph.D. degrees from the University of Canterbury, Christchurch, New Zealand, in 1973 and 1976, respectively.

He was previously with the New Zealand Electricity Department, Wellington, New Zealand, National University of Singapore, Singapore and the State Energy Commission of Western Australia, Perth, Australia. He is now a Professor in the School of Electrical and Electronic Engineering, Nanyang Technological University, Singapore. His research interests include power system control, and renewable and energy storage systems.

Chun Yang received the B.Sc. degree from the Department of Thermal Engineering at Tsinghua University, Beijing, China in 1985, the Master's degree in engineering thermophysics from the University of Science and Technology of China, Hefei, China in 1988, and the Ph.D. degree in mechanical engineering from the University of Alberta, Edmonton, Canada, in 1999.

In 1999, he joined Nanyang Technological University, and now is an Associate Professor in the School of Mechanical and Aerospace Engineering. His current research interests include heat and mass transfer, electrokinetic transport phenomena, microfluidics, and microscale flow. 